\title{
Participatory design of street vendor tents at PKL Wahidin, Yogyakarta City
}

\section{Desain partisipatif tenda pedagang kaki lima di PKL Wahidin, Kota Yogyakarta}

\author{
Tutun Seliari, Imelda Irmawati Damanik, Yohanes Satyayoga Raniasta \\ Departemen Arsitektur, Fakultas Arsitektur dan Desain, Universitas Kristen Duta Wacana \\ Jl. Dr. Wahidin Sudirohusodo 5-25, Yogyakarta, 55224 Indonesia
}

\section{ARTICLE INFO \\ Received: 2021-02-15 \\ Revised: 2021-04-09 \\ Accepted: 2021-06-14 \\ Keywords: \\ Community-based design, Participatory design, Street vendors, Tents}

\section{ABSTRACT}

The existence of street vendors (in Indonesian called Pedagang Kaki Lima/PKL), who are often shabby and disturb the visual image of the city, has become an issue raised in this community service program. This service program assists PKL Communities along Wahidin Sudirohusodo Street Yogyakarta (in front of the Duta Wacana Christian University Campus). The PKL Wahidin community has the intention to improve itself to organize street vendors that involve relevant stakeholders (according to the Yogyakarta City 'gandeng-gendong' program) it is hoped that it can become an identity for an image of a city in Yogyakarta. The process of designing street vendors tents using participatory design methods, community-based design with stages in the form of surveys, observations, interviews, Focus Group Discussion (FGD), and making tent design mockups. The participatory design method chosen was expected to make the community have 'sense of belonging' of the arrangement of street vendors along Wahidin Street so that sustainability would be created. This tent design can later be moved (movable) and following user needs and because the location of the design sidewalks remains environmentally friendly to pedestrians.
(C)2021 Published by University of Merdeka Malang. This is an open access article distributed under the CC BY-SA 4.0 license (https://creativecommons.org/licenses/by-sa/4.0/)

How to cite: Seliari, T., Damanik, I. I., \& Raniasta, Y. S. (2021). Participatory design of street vendor tents at PKL Wahidin, Yogyakarta City. Abdimas: Jurnal Pengabdian Masyarakat Universitas Merdeka Malang, 6(4), 575-587. https://doi.org/10.26905/abdimas.v6i4.5468

\section{PENDAHULUAN}

Keberadaan kampus Universitas Kristen Duta Wacana (UKDW) telah menjadi magnet bagi perkembangan kawasan, dimana kampus telah menarik mahasiswa dari luar kota untuk datang dan bermukim. Hal ini memberikan dampak positif bagi masyarakat terutama pada aspek ekonominya. Guna menunjang aktivitas kampus, maka berkembanglah Jl. Dr. Wahidin Sudirohusodo menjadi kawasan komersial, dengan keberadaan bangunan toko di sepanjang jalan. Selain itu, berkembang juga deretan pedagang kaki lima (street vendors) di sepanjang jalur pejalan kaki yang melangsungkan aktivitasnya sepanjang hari, menjual berbagai makanan dan minuman. Meskipun aktivitas perbelanjaan saat ini 
ABDIMAS: Jurnal Pengabdian Masyarakat Universitas Merdeka Malang Volume 6, No. 4, November 2021: 575-587

bisa dilakukan melalui internet, berbelanja dengan melihat langsung barang maupun kuliner tidak bisa ditinggalkan (Saraswati, 2019). Aktivitas pedagang kaki lima (PKL) di kota-kota besar sering kontroversial dan terkadang illegal karena menduduki ruang publik (Suryanto et al., 2020).

Pedagang kaki lima (PKL) memberikan kontribusi yang signifikan terhadap citra kawasan. Keberadaannya di atas jalur pejalan kaki sepanjang jalan utama menjadi elemen street scape yang menonjol. PKL memiliki sisi positif dan negatif, sisi positifnya PKL mampu menciptakan lapangan pekerjaan, sedangkan sisi negatifnya keberadaan PKL yang tidak tertib justru menjadi beban bagi kota. Di satu sisi PKL memberikan peluang usaha bagi masyarakat, namun di sisi lain PKL dianggap mengganggu ketertiban dan kebersihan daerah (Yusida et al., 2019). Hal senada juga disampaikan Rambing et al. (2019) PKL yang tidak teratur mengganggu ketertiban, keindahan, serta kebersihan lingkungan di wilayah kota dan juga masalah limbah atau sampah. Namun di sisi lain PKL dapat membantu masyarakat khususnya mahasiswa karena lokasinya yang strategis dan harga lebih terjangkau (Widjajanti, 2012). Keberadaan PKL walaupun sebagai sektor informal mendapat dukungan keberadaannya oleh Pemerintah Kota Yogyakarta dengan adanya peraturan walikota terkait dengan keberadaan PKL. Berdasarkan Peraturan Walikota Yogyakarta No. 62 Tahun 2009, pedagang kaki lima adalah penjual barang dan jasa yang menggunakan daerah milik jalan atau fasilitas umum dan bersifat sementara/tidak menetap, lokasi PKL antara lain trotoar pada ruas jalan tertentu dan khusus untuk yang melakukan kegiatan usaha di depan perguruan tinggi harus mendapatkan persetujuan dari pimpinan perguruan tinggi dan menjalankan usahanya pada malam hari serta mendukung sebagai kawasan wisata kuliner.

PKL di sepanjang ruas JI. Dr. Wahidin Sudirohusodo (selanjutnya disebut komunitas PKL Wahidin) berada di depan kampus UKDW (secara administrasi berada di Kelurahan Kotabaru dan PKL di seberang kampus UKDW masuk wilayah Kampung Klitren), mereka tergabung dalam sebuah komunitas Koperasi Persatuan Pedagang Kaki Lima Yogyakarta (PPKLY) dan Asosiasi Pedagang Kaki Lima (APKLI) Kota Yogyakarta. Seiring dengan penguatan citra kota Yogyakarta yang saat ini dilakukan oleh Pemerintah Kota Yogyakarta di kawasan Kotabaru dengan penataan pedestriannya, komunitas PKL Wahidin juga mempunyai keinginan untuk memperbaiki citranya sebagai bagian dari kawasan Kotabaru-Klitren. Berdasarkan wawancara dengan Bapak Wawan Suhendra selaku ketua APKLI Kota Yogyakarta, para PKL ini mempunyai slogan "Indah Tanpa Memindah", dengan harapan keberadaan mereka di sepanjang Jl. Dr. Wahidin Sudirohusodo justru dapat memperkuat citra kawasan di Kotabaru.

Keberadaan PKL sebagai elemen sementara yang tidak terencana di ruang kota dengan ketidakteraturannya dan penampilan yang kurang sedap dipandang, dianggap 'out of place' terutama dari sudut pandang elit perkotaan sehingga memicu tindakan menghapusnya dari ruang kota, namun yang perlu menjadi perhatian penting mengingat potensi PKL dapat berkontribusi pada identitas lokal suatu tempat sehingga PKL memerlukan perlakuan yang berbeda bergantung pada konteksnya (Yatmo, 2008). Permasalahan yang dihadapi oleh PKL Wahidin antara lain berupa desain tampilan dari warung tenda. Saat ini kondisi tenda rata-rata pedagang kaki lima tersebut relatif tidak rapi dan kurang menarik. Tenda satu dengan lainnya terbuat dari berbagai macam bentuk, ukuran, serta bahan yang berbeda-beda, relatif masih seadanya. Hal ini menyebabkan kawasan yang padat ini menjadi terkesan kumuh. Keadaan tersebut tidak hanya dirasakan oleh masyarakat umum ataupun pengunjung tetapi juga para pedagang di komunitas PKL Wahidin. Selain permasalahan desain tenda kendala lain yang 


\section{Participatory design of street vendor tents at PKL Wahidin, Yogyakarta City}

Tutun Seliari, Imelda Irmawati Damanik, Yohanes Satyayoga Raniasta

dihadapi pedagang adalah sistem pemasangan tenda, karena menurut peraturan tenda tidak boleh permanen sehingga tenda harus bongkar pasang. Dalam satu hari PKL di Jalan Wahidin ini terbagi menjadi 2 yaitu pedagang yang berjualan pagi hingga siang hari dan sore hingga malam hari. Waktu dan efisiensi cara pemasangan tenda juga menjadi kendala bagi para pedagang, tenda yang saat ini sebagian besar dengan sistem knock down membutuhkan waktu yang tidak singkat untuk pemasangan dan memerlukan ruang yang tidak ringkas untuk penyimpanannya. Kehadiran PKL di ruang perkotaan dapat menimbulkan masalah lingkungan walaupun kontribusinya sangat besar bagi mata pencahariaan perkotaan. Intervensi yang tepat dalam pembangunan sosial, perencanaan kota, dan desain dapat mengaktifkan fungsi perekonomian informal secara menguntungkan bagi daerah perkotaan (Suryanto et al., 2020). Sistem swa-kelola dan kerjasama antar pemangku kepentingan sangat berperan bagi PKL dalam menentukan ruang, sirkulasi, utilitas, dan masalah lainnya untuk memaksimalkan manfaat dan meminimalkan kelemahan kegiatan ekonomi informal di ruang publik. PKL adalah aktivitas wirausaha kreatif dan transformatif yang meningkatkan kesejahteraan individu dan kolektif (Giraldo et al., 2020).

Sasaran dari kegiatan Pengabdian kepada Masyarakat (PKM) ini adalah Pedagang Kaki Lima (PKL) di sepanjang Jl. Dr. Wahidin Sudirohusodo Yogyakarta yang merupakan salah satu wujud dalam mendukung program Gandeng Gendong yang dicanangkan oleh Pemerintah Kota Yogyakarta. Program Gandeng Gendong merupakan program kerjasama stakeholder pembangunan dalam rangka pemberdayaan dan peningkatan ekonomi masyarakat, peningkatan kesejahteraan, dan kemajuan lingkungan (Peraturan Walikota Yogyakarta No. 23 Tahun 2018). Gandeng Gendong melibatkan 5 unsur yang dikenal dengan 5K, yaitu Kota (pemerintah), Kampung, Komunitas, Korporasi, dan Kampus (BPPM DIY, 2018). Program PKM dilaksanakan bekerjasama dengan mitra yaitu APKLI dan PPKLY sebagai pihak yang mewadahi komunitas PKL di Yogyakarta, Pemerintah Kelurahan Kotabaru, Presidium Paguyuban Malioboro, Kampung Klitren, dan Kampus UKDW (Lembaga Penelitian dan Pengabdian Masyarakat UKDW; Laboratorium Lingkungan Kota Permukiman Fakultas Arsitektur dan Desain UKDW).

Secara jangka panjang kegiatan pengabdian ini bertujuan untuk menata lokasi berjualan PKL di sepanjang J. Dr. Wahidin Sudirohusodo. Kegiatan PKM ini adalah langkah awal dari tahapan kegiatan penataan dengan mengidentifikasi tipologi sarana berjualan PKL Wahidin dan mendesain tenda secara partisipatif sesuai dengan lokasi dan kebutuhan aktivitas PKL.

\section{METODE}

Kegiatan pengabdian ini dilakukan dengan menggunakan metode desain partisipatif yang berupa desain berbasis komunitas dengan tahapan meliputi survei, observasi, wawancara, Focus Group Discussion (FGD), dan pembuatan maket desain model tenda. Dalam kegiatan pengabdian ini, tim pendamping melakukan kerjasama dengan beberapa organisasi, paguyuban, dan kelompok yang memiliki fokus pendampingan pada PKL, yaitu PPKLY, APKLI-Kota Yogyakarta, Kelurahan Kotabaru, Presidium Paguyuban Malioboro, Kampung Klitren, dan Kampus UKDW. Kerjasama ini membuat alternatif pengembangan desain tenda sebagai proses awal penataan PKL Wahidin yang ke depannya diharapkan dapat berkontribusi terhadap citra ruang kota. 
ABDIMAS: Jurnal Pengabdian Masyarakat Universitas Merdeka Malang Volume 6, No. 4, November 2021: 575-587

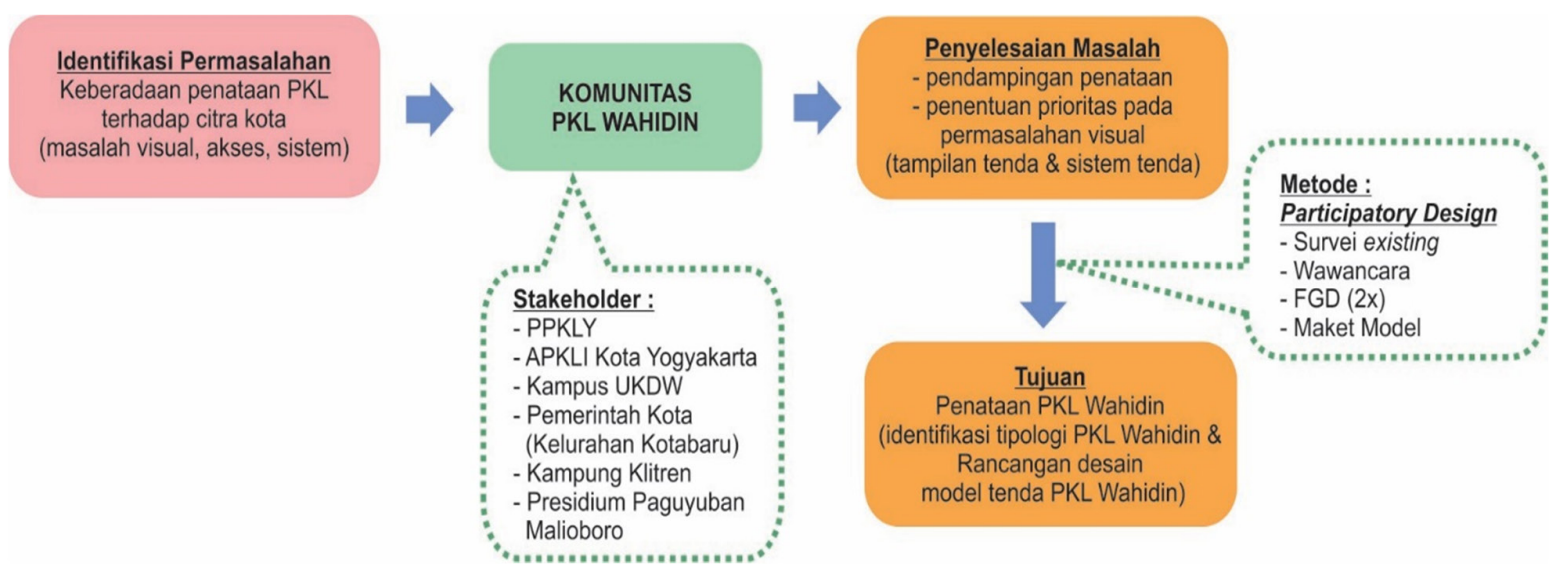

Gambar 1. Alur pelaksanaan PKM

Kegiatan PKM dilakukan dengan melakukan FGD sebanyak 2 kali untuk mendapatkan pendapat dari komunitas PKL Wahidin, pendapat pemerintah, paguyuban, warga, dan akademisi. Hasil observasi existing dan FGD diharapkan memberikan petunjuk untuk pemilihan material, struktur, dan modulmodul yang dapat digunakan sebagai ide dasar tenda.

Tabel 1. Pelaksanaan program PKM

\begin{tabular}{|c|c|c|c|c|c|}
\hline Kegiatan & Tujuan & Output & Waktu & Lokasi & Stakeholder \\
\hline $\begin{array}{l}\text { Survei existing } \\
\text { \& wawancara } \\
\text { komunitas PKL }\end{array}$ & $\begin{array}{l}\text { Memetakan kondisi } \\
\text { existing PKL secara spasial }\end{array}$ & $\begin{array}{l}\text { Peta existing, dan } \\
\text { tipologi PKL }\end{array}$ & Oktober 2019 & $\begin{array}{l}\text { Sepanjang Jl. } \\
\text { Dr. Wahidin } \\
\text { Sudirohusodo, } \\
\text { Yogyakarta (depan } \\
\text { Kampus UKDW) }\end{array}$ & $\begin{array}{l}\text { Tim PKM, komunitas PKL } \\
\text { Wahidin }\end{array}$ \\
\hline FGD I & $\begin{array}{l}\text { Penggalian permasalahan } \\
\text { dan kebutuhan dan } \\
\text { penjaringan ide }\end{array}$ & $\begin{array}{l}\text { Draft ide } \\
\text { penataan } \mathrm{PKL} / \mathrm{ide} \\
\text { awal rancangan } \\
\text { tenda }\end{array}$ & $\begin{array}{l}7 \text { November } \\
2019\end{array}$ & Kampus UKDW & $\begin{array}{l}\text { Tim PKM, komunitas PKL } \\
\text { Wahidin, PPKLY, APKLI, } \\
\text { Presidium Paguyuban } \\
\text { Malioboro, warga Kampung } \\
\text { Klitren, Kelurahan Kotabaru }\end{array}$ \\
\hline FGD II & Draft rancangan tenda & $\begin{array}{l}\text { Ide rancangan } \\
\text { tenda }\end{array}$ & $\begin{array}{l}2 \text { Desember } \\
2019\end{array}$ & Kampus UKDW & Kampus UKDW \\
\hline $\begin{array}{l}\text { Pengolahan } \\
\text { data }\end{array}$ & $\begin{array}{l}\text { Mengolah data } \\
\text { hasil survei existing, } \\
\text { wawancara, dan FGD }\end{array}$ & $\begin{array}{l}\text { Konsep rancangan } \\
\text { tenda }\end{array}$ & $\begin{array}{l}\text { Januari- } \\
\text { februari } 2020\end{array}$ & Kampus UKDW & $\begin{array}{l}\text { Tim PKM, komunitas PKL } \\
\text { Wahidin }\end{array}$ \\
\hline $\begin{array}{l}\text { Pembuatan } \\
\text { maket tenda }\end{array}$ & $\begin{array}{l}\text { Visualisasi rancangan } \\
\text { tenda }\end{array}$ & $\begin{array}{l}\text { Maket dan } \\
\text { gambar } \\
\text { rancangan }\end{array}$ & $\begin{array}{l}\text { Maret-April } \\
2020\end{array}$ & Kampus UKDW & $\begin{array}{l}\text { Tim PKM, komunitas PKL } \\
\text { Wahidin }\end{array}$ \\
\hline
\end{tabular}

\section{HASIL DAN PEMBAHASAN}

Program pengabdian ini dilakukan melalui 2 tahapan, yaitu pemetaan block plan existing (melalui survei dan wawancara) dan perancangan tenda (melalui FGD dan maket model). 
Participatory design of street vendor tents at PKL Wahidin, Yogyakarta City

Tutun Seliari, Imelda Irmawati Damanik, Yohanes Satyayoga Raniasta

\section{Pemetaan block plan existing PKL Wahidin}

Pemetaan block plan existing PKL Wahidin dilakukan untuk mendapatkan tipologi tenda PKL. Diawali dengan survei dan wawancara ke semua warung PKL baik yang berjualan pada pagi hari ataupun pada siang hari. Dari hasil survei didapatkan informasi bahwa komunitas PKL Wahidin sebanyak 33 warung PKL.

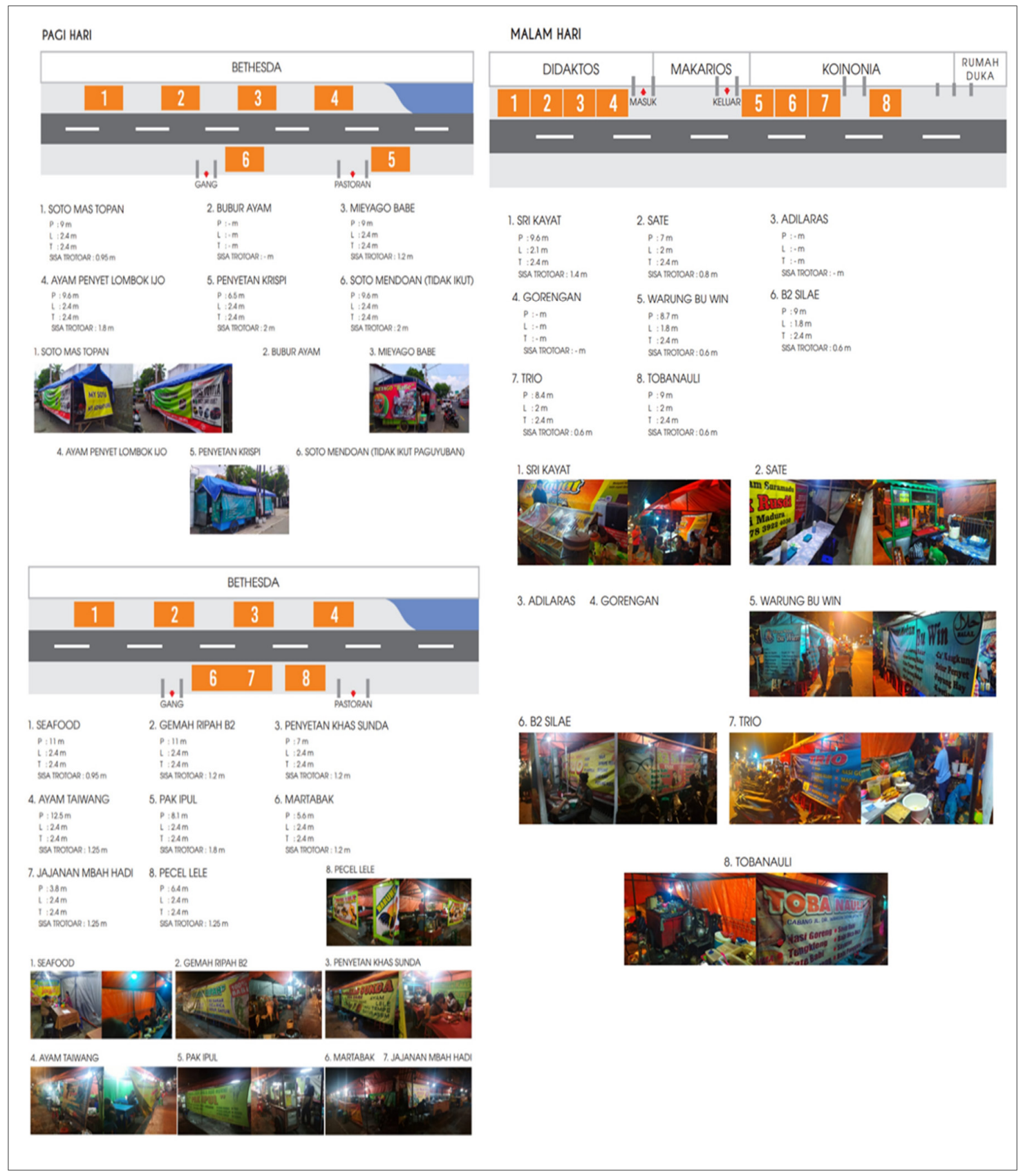

Gambar 2. Pemetaan block plan existing PKL Wahidin 
ABDIMAS: Jurnal Pengabdian Masyarakat Universitas Merdeka Malang Volume 6, No. 4, November 2021: 575-587

Dari hasil survei warung tenda PKL Wahidin didapatkan 3 tipologi. Penentuan tipologi didasarkan pada ukuran tenda, tipe kebutuhan atribut tenda berdasarkan jenis dagangan PKL. 3 tipologi tersebut yaitu: (1) Tipologi 1 (depan UKDW): Tenda PKL dengan lebar 1,8-2 meter, panjang 7-9.6 meter; (2) Tipologi 2 (utara UKDW): Tenda PKL dengan lebar 2,4 meter, panjang 3-12,5 meter; (3) Tipologi 3: bentuk warung PKL berupa kios. Identifikasi tipologi warung tenda ini menjadi langkah awal proses identifikasi elemenelemen tenda yang akan dikembangkan bersama dengan komunitas PKL. Dari tipologi ini ditemukan informasi mengenai ukuran (panjang, lebar, dan tinggi), material apa saja yang digunakan, orientasi bukaan dan sirkulasi dalam maupun luar tenda, serta pola-pola kegiatan berjualan yang terjadi, terutama pola interaksi antara penjual dan pembeli. Dari sisi desain, juga dapat dilakukan pengamatan mengenai zonasi dari warung tenda, yaitu ruang pelayanan/pemesanan, ruang memproses makanan/masakan, ruang untuk pengunjung/pembeli, ruang penyimpanan, dan ruang pembersihan. Selain itu, dapat juga diidentifikasi hal-hal yang lebih detail, misalnya mengenai warna yang digunakan pada penutup tenda, besar huruf dan komposisi perletakannya dan gambar lainnya yang memberikan citra khas warung tenda (Hermanto, 2018; Akbar et al., 2016).

Data di atas adalah data yang dikumpulkan dengan cara berpikir desain, untuk itu dibutuhkan konfirmasi dari komunitas PKL mengenai aspek apa saja yang mereka gunakan dalam pengambilan keputusan desain tenda yang digunakan selama ini. Konfirmasi ini akan membantu pemahaman praktis dalam mendesain, sekaligus juga menjadi kesempatan untuk memasukkan teori desain dalam proses berpikir kritis dan proses mendesain praktis. Hal ini menjadi titik penting dalam kolaborasi antara akademisi dan komunitas pedagang kaki lima untuk menyatukan perspektif desain tenda, yang nantinya akan menjadi bagian penataan kawasan yang lebih tertata indah dan bersih.

\section{Perancangan desain tenda PKL Wahidin}

\section{Focus Group Disscussion (FGD) I}

Menindaklanjuti hasil survei lapangan, maka diadakan Focus Group Discussion (FGD) dengan berbagai pihak yang memiliki kepentingan terhadap keberadaan PKL di sepanjang jalan Dr. Wahidin Kota Yogyakarta. Kegiatan FGD dilakukan dengan tujuan: (1) Memaparkan temuan survei dan melakukan konfirmasi hasil identifikasi tenda; (2) Mendiskusikan serta menggali lebih detail terkait permasalahan dan kebutuhan para PKL. Agar keseluruhan tujuan FGD dapat tercapai, maka pelaksanaan FGD ini tidak hanya dari pihak tim pengabdian dengan mitra para PKL tetapi juga melibatkan stakeholder terkait antara lain Pemerintah Kelurahan Kotabaru, Babinsa Kelurahan Kotabaru, Presidium Paguyuban Kawasan Malioboro yang merupakan pendamping dari PKL di J Dr. Wahidin, dan perwakilan warga kampung Klitren, yang terdiri dari 19 orang peserta FGD ditambah dengan fasilitator FGD.

Pada paparan temuan survei dari tim pengabdian, peserta FGD mendapatkan informasi yang dijadikan acuan dalam diskusi detail permasalahan yang dihadapi oleh komunitas PKL dan kebutuhan yang perlu diprioritaskan dalam pengembangan tenda PKL. Dengan demikian, pada diskusi bagian ke2, yaitu menggali permasalahan dan kebutuhan komunitas $\mathrm{PKL}$, menjadi proses yang penting, karena membutuhkan tingkat partisipatori yang aktif dari setiap peserta FGD. Untuk itu, peserta FGD dibagi menjadi 3 kelompok, yang masing-masing kelompok beranggotakan 7-8 peserta. Setiap kelompok 
kemudian memilih tim yang akan mencatat poin-poin diskusi yang nantinya akan dibagikan kepada seluruh peserta.
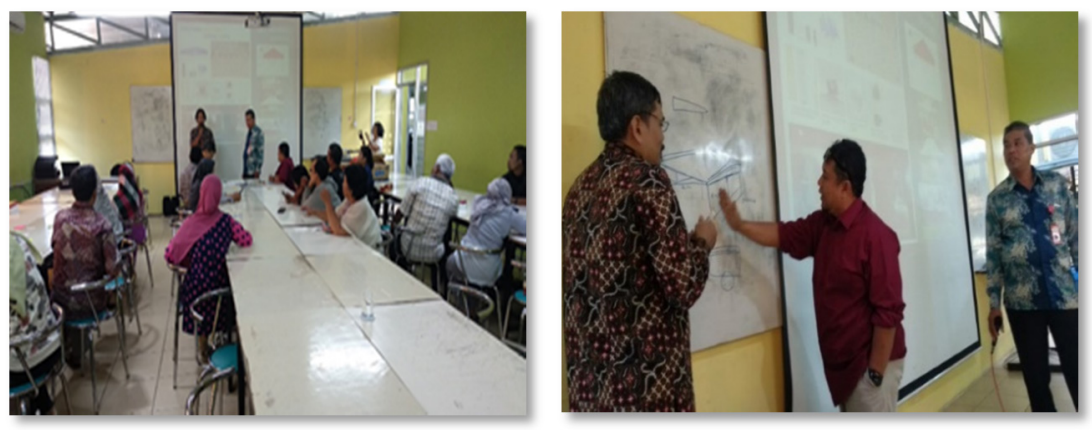

Gambar 3. Suasana pelaksanaan FGD I

Pada akhir diskusi, setiap kelompok memberikan usulan konsep desain tenda yang menjadi solusi untuk permasalahan dan kebutuhan PKL. Hasil diskusi berupa sketsa, deskripsi, dan diagram yang berisikan usulan, konsep maupun rekomendasi. Dari ke-3 hasil diskusi akan diambil buah pikiran yang paling baik dan paling cocok diterapkan pada lokasi PKL di Jalan Dr. Wahidin. Berikut adalah hasil dari diskusi pada FGD I: (1) Permasalahan utama yang dihadapi adalah: (a) Pemasangan tenda seperti efisensi waktu pemasangan, kepraktisan/efektivitas, desain visual tenda, dan kekuatan, tampias air hujan; (b) Akses pejalan kaki; (c) Sistem seperti tipologi PKL (jenis dagangan), pengolahan air, sampah, cara penyajian; (2) Strategi yang akan dilakukan untuk meminimalisir dan menyelesaikan permasalahan tersebut dengan dengan strategi: (a) Penataan PKL; (b) Merancang desain tenda; (c) Memperbaiki sistem seperti sanitasi, sampah, kebersihan/higenitas, dan cara penyajian.

Peserta juga memberikan sketsa ide desain yang diinginkan, yang sesuai dengan kebutuhan kegiatan berdagang serta menyelesaikan permasalahan yang ditimbulkan oleh keberadaan warung tenda di tepi jalan. Selain sketsa ide, desain juga dibuatkan model konseptual (maket) dengan skala 1:20, untuk memberikan gambaran desain yang lebih terukur. Penataan PKL tidak hanya dari aspek estetika dan pemasangan tenda yang praktis dan efisien tetapi juga sistem yang terkait dengan cara penyajian, sampah, sanitasi, dan kebersihan/higenitas yang akan dilakukan secara bertahap.

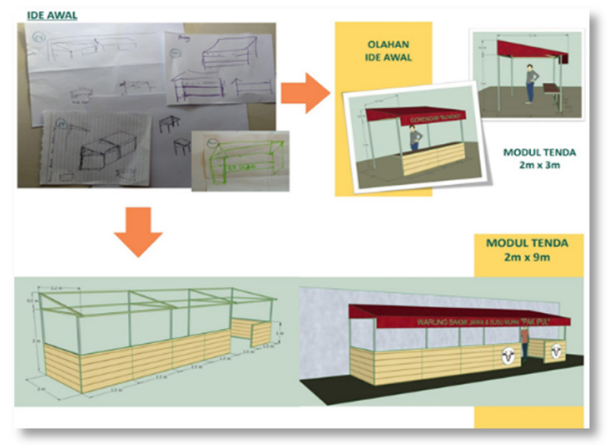

Gambar 4. Hasil desain partisipatif dari FGD I oleh Komunitas PKL Wahidin 
ABDIMAS: Jurnal Pengabdian Masyarakat Universitas Merdeka Malang Volume 6, No. 4, November 2021: 575-587

Diskusi di kelompok besar didapatkan hasil bahwa jargon komunitas PKL di Yogyakarta "Indah Tanpa Memindah" dijadikan sebagai semangat dalam melakukan penataan dan perancangan desain tenda, yang akan diwujudkan dalam rangkaian kegiatan bersama antara tim pengabdian, komunitas PKL, dan semua stakeholder yang terkait dengan hal ini. Pada akhir kegiatan FGD I ditetapkan prioritas, yaitu melanjutkan sharing ide desain dengan melakukan FGD lanjutan yang fokus pada alternatif desain, sehingga ide-ide yang telah terkumpul pada tahap FGD I dapat dikonkritkan menjadi desain yang aplikatif, dan yang paling utama adalah mampu menjawab tantangan desain serta menjadi solusi yang komprehensif untuk permasalahan lingkungan akibat keberadaan warung tenda di Jalan Dr. Wahidin Kota Yogyakarta.

\section{Focus Group Discussion (FGD) II}

FGD II dilakukan dengan agenda pembahasan draft rancangan tenda. Hasil diskusi dari FGD I menjadi bekal untuk mendapatkan alternatif rancangan tenda. Alternatif rancangan model tenda disajikan dan disepakati bersama oleh bapak ibu PKL dan stakeholder terkait untuk dikembangkan sistemnya dan dibuat maket model untuk merepresentasikannya (Gambar 5). Alternatif desain yang telah diolah dari ide awal kelompok pada FGD I, yang disajikan dalam bentuk maket model memudahkan komunitas PKL mencermati dan melakukan analisis sederhana. Usulan yang diberikan untuk perbaikan desain adalah: (1) Bentuk atap perlu dicari alternatif bentuknya, agar tidak memberikan beban tambahan pada struktur tenda; (2) Bentuk atap dan ukurannya perlu dicermati untuk mengatasi tampias air pada saat musim hujan; (3) Sistem rangka yang diusulkan adalah sistem lipat (folding) dan geser (sliding), sehingga rangka tenda lebih ringkas dan mudah untuk dipindahkan. Selain itu berat rangka juga harus dipertimbangkan, mengingat rangka tenda ini diangkat-dipasang-dibongkar dan diangkut kembali setiap kali pedagang kaki lima berjualan; (4) Usulan berikutnya adalah diharapkan desain baru diupayakan untuk dapat menggunakan material tenda yang lama, dengan tujuan untuk mengurangi biaya dan keberlanjutan; (5) Tenda yang mudah dipindahkan (moveable), dengan harga yang terjangkau (affordable).

Dari diskusi FGD II ini, para peserta sepakat bahwa aspek yang perlu diperhatikan adalah aspek efektivitas tenda, hal ini terkait pada ruang yang tersedia di jalur kaki lima di Jalan Dr. Wahidin dan efisiensi, terkait pada pembiayaan tenda yang diusahakan tetap terjangkau oleh penggunanya. Dengan demikian, tantangan desain ini menjadi sangat kompleks, tidak melulu pada estetika, tetapi juga pada prinsip-prinsip keberlanjutan desain, yaitu pemahaman akan konteks lingkungan, finansial, dan polapola aktivitas dalam menjalankan kegiatan perdagangan ala warung tenda.
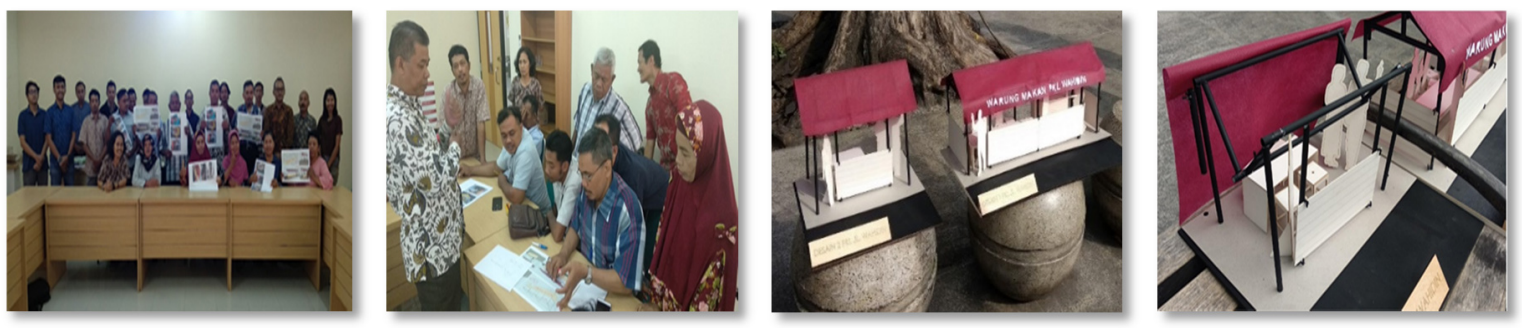

Gambar 5. Proses FGD II dan maket desain partisipatif hasil dari FGD II 


\section{Participatory design of street vendor tents at PKL Wahidin, Yogyakarta City}

Tutun Seliari, Imelda Irmawati Damanik, Yohanes Satyayoga Raniasta

Setelah melakukan review terhadap maket tenda, maka hasilnya kemudian diterjemahkan kembali dalam gambar desain 3D oleh tim PKM. Gambar 6 merupakan simulasi dari rancangan tenda PKL Wahidin yang dikembangkan berdasarkan hasil diskusi bersama komunitas PKL Wahidin. Tenda hasil simulasi ini dihasilkan dari mengambil salah satu tipologi dari hasil existing pemetaan yaitu tipologi 1 yang mempunyai lebar 2 meter. Kemudian dicoba dengan memasukkan data ketinggian, bentuk atap yang disarankan, posisi tulisan nama warung tenda, pembatas vertikal, dan akses sirkulasi keluar masuk tenda. Berikut ini adalah gambar maket modul rancangan tenda 1 modul dengan ukuran $2 \times 3$ meter beserta skema ketika dilipat agar menjadi lebih efesien saat dipindahkan.

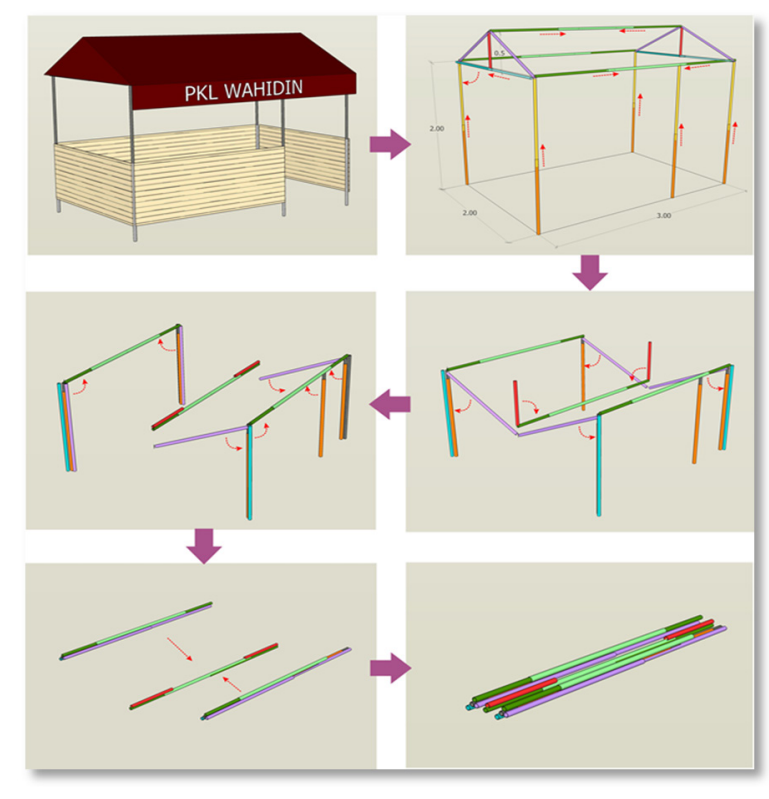

Gambar 6. Gambar rancangan tenda desain partisipatif

\section{Pembahasan}

Pada pelaksanaan kegiatan pengabdian masyarakat, terutama masyarakat sekitar kampus, tim telah memberikan perhatian pada proses pengumpulan informasi, yang diharapkan menjadi jembatan untuk melakukan penggalian ide kreatif dari komunitas pedagang kaki lima. Dalam hal ini, tim sangat dibantu dengan keterbukaan untuk bekerjasama dari Koperasi Persatuan Pedagang Kaki LIma Yogyakarta (PPKLY) dan Asosiasi Pedagang Kaki Lima (APKLI) Kota Yogyakarta. Ini adalah awal dari sebuah pemikiran desain tenda pedagang kaki lima dengan metode desain partisipatif.

Sejak awal, tim PKM telah menyadari bahwa pendampingan ini erat kaitannya dengan penataan kawasan, sehingga perlu menyelaraskan antara peraturan yang berlaku dengan pemikiran mengenai keberlangsungan PKL. Berdasarkan pemikiran tersebut, metode partisipatif menjadi pilihan dalam pelaksanaan kegiatan ini, sehingga dapat menjadi acuan bagi pemerintah dan juga bagi organisasi PKL yang ada. Pengaturan spasial pedagang kaki lima adalah fungsi umum di kota-kota, reformasi kebijakan yang mengakui PKL sebagai mata pencaharian yang sah merupakan pendekatan untuk 
ABDIMAS: Jurnal Pengabdian Masyarakat Universitas Merdeka Malang Volume 6, No. 4, November 2021: 575-587

memberikan alternatif pekerjaan, meningkatkan kesejahteraan rumah tangga, pendapatan pemerintah, dan penyediaan barang dengan harga murah di lokasi yang strategis untuk masyarakat umum (Roever \& Skinner, 2016). Kehadiran PKL di trotoar jalan akan menimbulkan masalah, namun di sisi lain, kehadiran PKL juga memberi manfaat fungsi jasa bagi kawasan sekitar, terutama pada mahasiswa jika dipandang dari konteks lokasi studi. Kawasan Jalan Wahidin merupakan ruang kota yang menyediakan jasa pendukung kegiatan mahasiswa, termasuk di dalamnya penyediaan makanan. Dari survei yang dilakukan, didapatkan data jenis makanan yang dijual pedagang PKL Wahidin adalah makanan yang disukai oleh orang muda, seperti pecel lele, ayam goreng, aneka gorengan, soto, dan bubur ayam. Namun disisi lain, keberadaan PKL tidak hanya perkara penyediakan makanan bagi mahasiswa, tetapi juga memberikan kontribusi yang signifikan terhadap kemacetan jalan, kebersihan-kekumuhan kawasan, dan perizinan berdagang. PKL tetap ingin menjalankan aktivitas perekonomiannya untuk kebutuhan sehari-hari dan menunjang perekonomian daerah, tetapi disisi lain keberadaannya terhadap fungsi tata ruang kota perlu memperhatikan aspek lingkungan secara optimal (Puspitasari, 2010). Kedua kondisi yang berjalan beriringan ini harus didudukkan dengan jernih, sehingga kota (pemerintah), kampus, kampung, komunitas, dan korporasi dapat melihat posisi masing-masing dalam permasalahan ini dan memiliki pemikiran solusi praktis serta keputusan strategis dalam penyelesaian permasalahan.

Kegiatan FGD sudah dilakukan sebanyak 2 kali, menghasilkan diskusi yang cukup bernas dalam pengambilan langkah solusi, baik dari sudut kebijakan, program pendukung kelayakan dagangan serta desain tenda yang memiliki estetika dan efisiensi ruang. Pemerintah Kota lewat kelurahan telah menyampaikan poin-poin yang harus dipertimbangkan dalam penyelenggaraan perdagangan informal dalam bentuk warung tenda di sepanjang jalan Dr. Wahidin. Komunitas pedagang kaki lima mendapatkan gambaran mengenai standar-standar kebersihan dan kelayakan ruang bekerja (berdagang), juga mendapatkan informasi umum mengenai manfaat dari ruang-ruang publik yang selama ini diambil alih dan dijadikan ruang privat. Hal ini akan membangun tolerasi bagi pengguna jalan, sehingga ada pengaturan dalam pemanfaatan trotoar. Dari sisi kampung sebagai ruang yang menjadi bagian dari tempat tinggal mahasiswa (kost) juga mengetahui kebutuhan pendukung yang disediakan oleh para PKL. Sedangkan kampus yang menjadi tempat mahasiswa menuntut ilmu berpartisipasi untuk melakukan pendampingan terhadap PKL Wahidin, melalui PPKLY, APKLI, dan komunitas PKL Wahidin untuk melakukan kajian yang berkaitan dengan desain tenda yang memperhatikan pola perilaku bekerja (berdagang) dan struktur tenda yang ringkas, ringan dan mudah dibongkar-pasang. Seluruh pelaku Gandeng Gendong memiliki peran dalam proses pengabdian ini.

Hasil diskusi FGD juga mendukung beberapa penelitian yang telah dilakukan, bahwa ada 9 faktor yang berpengaruh pada penataan PKL, yaitu: (1) Kemacetan; (2) Kebersihan; (3) Insentif dan disentif; (4) Perizinan; (5) Pembinaan; (6) Penyuluhan; (7) Kerjasama dengan pemerintah; (8) Jaminan perlindungan; dan (9) Ketertiban dan keindahan (Fajrin \& Rahmawati, 2016). Faktor-faktor tersebut digali secara terbuka dan menjadi refleksi bagi semua pihak Gandeng Gendong untuk membuat prioritas dan menyusun strategi kolaborasi yang dapat dilakukan, agar semua perencanaan menghasilkan program yang berkelanjutan.

Di lain pihak, tim pengabdian juga menyadari bahwa proses desain tidak dapat berjalan hanya dalam satu program pengabdian saja, mengingat faktor-faktor yang harus dipertimbangkan dalam 


\section{Participatory design of street vendor tents at PKL Wahidin, Yogyakarta City}

Tutun Seliari, Imelda Irmawati Damanik, Yohanes Satyayoga Raniasta

desain yang merupakan catatan dari FGD. Untuk itu, tim pengabdian melakukan penyusunan kembali strategi desain, sehingga desain tenda akan menghasilkan tenda tepat guna. PKL menggunakan sarana dagang berupa warung tenda untuk kemudahan bongkar pasang dan dibawa pulang (Widjajanti, 2012). Lebar trotoar yang dibatasi dan ketinggian tenda, salah satu realisasi pola penataan adalah dengan penyeragaman tenda dan gerobak dagangan. Ruas jalan yang diperbolehkan untuk PKL memiliki trotoar minimal 1,5 meter dan PKL hanya diperbolehkan menggunakan 60\% (persen) dari lebar trotoar dan wajib menyisakan untuk sirkulasi pejalan kaki, untuk lebar trotoar lebih dari 3 meter, lebar tempat usaha maksimal 2 meter (Puspitasari, 2010; Peraturan Walikota Yogyakarta No. 62 Tahun 2009; Peraturan Walikota Yogyakarta No.45 Tahun 2007). Berdasarkan dari hasil pemetaan tipologi exsisting sarana dagang PKL Wahidin menggunakan sarana dagang berupa tenda dengan rangka besi dan atau kayu. Tenda yang dirancang secara partisipatif bersama PKL Wahidin ini menggunakan ukuran modul lebar 2 meter dan panjang 3 meter (menggambil lokasi di bagian utara yang mempunyai lebar trotoar 3 meter). Melalui modul ini nantinya dapat disesuaikan dengan kebutuhan dari masing-masing PKL.

Semua pihak sedang melanjutkan kegiatan sesuai dengan perannya masing-masing, tetap melakukan komunikasi untuk menjaga kesinambungan kegiatan dan kerjasama. Sehingga proses penajaman keilmuan (desain) masih dilakukan, PKL tetap menjalankan aktivitas perekonomiannya, pemerintah melakukan pengaturan dan menyusun kebijakan-kebijakan serta komunitas kampung yang turut menjaga keberlangsungan kegiatan PKL Wahidin. Harapan untuk terwujudnya PKL yang indah tanpa memindah, bersih tapi terjangkau, serta ruang aman dan nyaman di dalam ruang kota segera terwujud.

\section{SIMPULAN DAN SARAN}

Keberadaan kampus yang menjadi mitra dari PKL melalui program pengabdian masyarakat menjadi suatu kolaborasi yang sangat baik karena bisa bersinergi dan berkolaborasi. Keberadaan PKL yang notabene sering dianggap kumuh dan mengganggu citra visual kota, dengan niat yang sungguhsungguh dari komunitas PKL Wahidin sendiri untuk berbenah diri justru nantinya diharapkan dapat menjadi sebuah identitas bagi sebuah citra kota. Keberadaan PKL yang berada di trotoar dengan proses perancangannya yang melibatkan berbagai stakeholder (sesuai dengan program gandeng gendong Kota Yogyakarta) diharapkan dapat memberikan kenyamanan publik dan juga memberikan manfaat kepada komunitas PKL, berupa tenda yang ramah lingkungan dan meningkatkan citra kota.

Proses perancangan tenda PKL ini yang menggunakan metode desain partisipatif yang berupa survei, observasi, wawancara, Focus Group Discussion (FGD), pembuatan maket model desain tenda, memang mempunyai kendala yaitu proses waktu yang lama, namun diharapkan hasilnya nanti dapat mengakomodir kebutuhan dari berbagai pihak. Metode desain partisipatif ini dipilih agar komunitas nantinya mempunyai rasa 'sense of belonging' terhadap penataan PKL di sepanjang Jl. Wahidin sehingga akan tercipta keberlanjutan. Saran selanjutnya untuk kegiatan pendampingan ini adalah melakukan studi banding rancangan tenda PKL di tempat lain dan ujicoba pembuatan model rangka tenda dengan ukuran sebenarnya sehingga bisa diuji efektivitas dalam penggunaannya. Adanya pandemi COVID-19 juga sangat berdampak terhadap keberadaan aktivitas ekonomi komunitas PKL Wahidin. Pendampingan 
ABDIMAS: Jurnal Pengabdian Masyarakat Universitas Merdeka Malang Volume 6, No. 4, November 2021: 575-587

PKL terkait dengan pemasaran dan penguatan kapasitas komunitas PKL diperlukan untuk mejaga keberlangsungan komunitas PKL Wahidin.

\section{UCAPAN TERIMA KASIH}

Ucapan terimakasih kami sampaikan kepada LPPM Universitas Kristen Duta Wacana untuk hibahnya melalui program Pengabdian kepada Masyarakat (PKM).

\section{DAFTAR PUSTAKA}

Akbar, T., Zainal, A., \& Raden, M. (2016). Tipografi vernakular pada warung tenda kaki lima di Jakarta. Jurnal Dimensi DKV Seni Rupa dan Desain, 1(2), 175-183.

http://dx.doi.org/10.25105/jdd.v1i2.1359

Badan Pemberdayaan Perempuan dan Masyarakat Daerah Istimewa Yogyakarta (BPPM DIY). (2018). Buku pedoman pemberdayaan masyarakat berbasis Segoro Amarto. Yogyakarta: Badan Pemberdayaan Perempuan dan Masyarakat Daerah Istimewa Yogyakarta.

Fajrin, A. R. M., \& Rahmawati, D. (2016). Faktor-faktor yang berpengaruh dalam penataan pedagang kaki lima (PKL) pada koridor Jalan Pasar Besar Kota Malang. Jurnal Teknik ITS, 5(1). https://doi.org/10.12962/j23373539.v5i1.11414

Giraldo, M., Garcia-Tello, L., \& Rayburn, S. W. (2020). Street vending: Transformative entrepreneurship for individual and collective well-being. Journal of Services Marketing, 34(6), 757-768. https://doi.org/10.1108/JSM-08-2019-0322

Hermanto, Y. A. L. (2018). Identifikasi ilustrasi-tipografi graphic vernacular sebagai sistem tanda \& identitas warung tenda di Kota Malang. JADECS: Jurnal of Art, Design, Art Education \& Cultural Studies, 3(2), 74-83. https://doi.org/10.17977/um037v3i2p74-83

Peraturan Walikota Yogyakarta Nomor 23 Tahun 2018 tentang Program Gandeng Gendong Kota Yogyakarta.

Peraturan Walikota Yogyakarta Nomor 62 Tahun 2009 Perubahan Peraturan Walikota Yogyakarta Nomor 45 Tahun 2007 tentang Petunjuk Pelaksanaan Peraturan Daerah Kota Yogyakarta Nomor 26 Tahun 2002 Tentang Penataan Pedagang Kaki Lima.

Puspitasari, D. E. (2010). Penataan pedagang kaki lima kuliner untuk mewujudkan fungsi tata ruang kota di Kota Yogyakarta dan Kabupaten Sleman. Mimbar Hukum: Fakultas Hukum Universitas Gadjah Mada, 22(3), 588-606. https://doi.org/10.22146/jmh.16244

Rambing, R. K., Tasik, F. C. M., \& Mumu, R. (2019). Kontrol sosial terhadap PKL (pedagang kaki lima) di Kompleks Pasar Bersehati Calaca Kecamatan Wenang Kota Manado. Holistik: Journal of Social and Culture, 12(4), 1-18.

Roever, S., \& Skinner, C. (2016). Street vendors and cities. Environment and Urbanization, 28(2), 359374. https://doi.org/10.1177/0956247816653898

Saraswati, T. (2019). Perspektif Jalan Malioboro di Yogyakarta pada era revolusi industri 4.0. Ruang: Jurnal Lingkungan Binaan (Space: Journal of The Built Environment), 6(2), 187-200. 


\section{Participatory design of street vendor tents at PKL Wahidin, Yogyakarta City}

Tutun Seliari, Imelda Irmawati Damanik, Yohanes Satyayoga Raniasta

Suryanto, M. E., Adianto, J., \& Gabe, R. T. (2020). Accommodating the informal economy in public space: The intricate political and spatial arrangements at an Indonesian Street Market. Urbani Izziv, 31(1), 89-100. https://doi.org/10.5379/urbani-izziv-en-2020-31-01-003

Widjajanti, R. (2012). Karakteristik aktivitas pedagang kaki lima di ruang kota (Studi kasus: Kawasan Pendidikan Tembalang, Kota Semarang). Jurnal Pembangunan Wilayah \& Kota, 8(4), 412-424. https://doi.org/10.14710/pwk.v8i4.6498

Yatmo, Y. A. (2008). Street vendors as "out of place" urban elements. Journal of Urban Design, 13(3), 387-402. https://doi.org/10.1080/13574800802320889

Yusida, E., Utomo, S. H., Qurrata, V. A. Q. A., Seprillina, L., Merlinda, S., \& Abbas, M. H. I. (2019). Kebijakan publik dan dampaknya terhadap aktivitas pedagang kaki lima (PKL): Studi kasus di Kota Batu. Jurnal Transaksi, 11(1), 44-50. 